\title{
Mucin-1 expression in endometrium is higher in polycystic ovary syndrome than in normal women
}

\author{
Uki Retno Budihastuti*, Sri Sulistyowati*, Eriana Melinawati*, Yohan Pamuji Marbun*
}

\begin{abstract}
*Department of Obstetrics and Gynecology, Faculty of Medicine, Universitas Sebelas Maret/ Dr. Moewardi General Hospital, Surakarta

\section{Correspondence:}

Uki Retno Budihastuti

Jl. Penggung - Jatinom Km 1 Jatiwiro, Blanceran, Karang Anom, Klaten Mobile: +628122656140

Email: ukiretno@staff.uns.ac.id ORCID ID: 0000-0003-0611-7464

Date of first submission, December 16 , 2019

Date of final revised submission, April 23, 2020

Date of acceptance, May 20, 2020

\section{BACKGROUND}

The polycystic ovary syndrome (PCOS) is caused by endocrine system dysfunction in women. MUCIN-1 (MUC-1) expression is found in endometrial tissues, which leads to implantation process dysfunction because of imbalance of trophoblast adhesion process. This study was conducted to compare endometrial MUC-1 expression between PCOS and normal women considering all existing external variables.

\section{METHODS}

This cross-sectional study was conducted in General Hospital Dr. Moewardi Surakarta. Endometrial samples were obtained from 30 infertile PCOS women based on Rotterdam criteria, and 30 normal women. Life style and reproductive data such as age, menstrual problems, menstrual cycle, age at menarche, and BMI were collected. Subjects underwent endometrial biopsy in luteinizing hormone $(\mathrm{LH})$ secretion phase $\mathrm{LH}+5$ days to $\mathrm{LH}+10$ days for immunohistochemistry (IHC) of MUC-1 expression. An independent- $t$ and multiple linear regression test were used to analyze the data at significance level of $\mathrm{p}<0.05$.
\end{abstract}

This open access article is distributed under a Creative Commons AttributionNon Commercial-Share Alike 4.0 International License

Cite this article as: Budihastuti UR, Sulistyowati S, Melinawati E, Marbun YP. Mucin-1 expression in endometrium is higher in polycystic ovary syndrome than in normal women. Univ Med 2020;39:74-80. doi: 10.18051/ UnivMed.2020.v39.74-80

\section{RESULTS}

Mean MUC-1 expression in the PCOS endometrium (49.66 \pm 47.79$)$ was significantly higher than in normal women $(7.66 \pm 14.55)(\mathrm{p}=0.03)$. Multivariate linear regression model of life style and reproductive variables with MUC-1 showed that PCOS $(\beta=29.54 ; 95 \% \mathrm{CI} 9.57-49.49 ; \mathrm{p}=0.004)$ and $\mathrm{BMI}(\beta=29.99 ; 95 \%$ CI 5.91-54.07; $\mathrm{p}=0.001)$ significantly increase MUC-1 expression. $\mathrm{PCOS}(\mathrm{Beta}=0.37)$ was more important than $\mathrm{BMI}(\mathrm{Beta}=0.30)$ in increasing the MUC-1 expression.

\section{CONCLUSION}

Expression of MUC-1 levels in the PCOS endometrium was higher than in normal women. This suggests that MUC-1 contributes to the unexplained reproductive failure in PCOS.

Keywords : Endometrium, MUC-1 expression, PCOS, normal women 


\section{INTRODUCTION}

Infertility in patients with polycystic ovary syndrome (PCOS) is caused by the dysfunction in endometrial receptivity contributing to failure of embryo implantation, since it is estimated that almost $75 \%$ of miscarriages are caused by implantation failure. ${ }^{(1-3)}$ For a successful pregnancy, competent blastocyst implantation into a receptive endometrium is needed. ${ }^{(4,5)}$ Abnormal endometrial receptivity will cause failure of embryo implantation and lowers the mean number of pregnancies in women with PCOS. In PCOS, factors that affect implantation undergo some changes causing the requirements for implantation to be incompletely fulfilled. ${ }^{(6)}$

Mucin 1 (MUC-1) is a protein that is highly expressed in endometrial luminal epithelium and glands, and is the first molecule on the surface of the uterus where the embryo is being implanted. Typically, MUC-1 is expressed in various luminal epithelial and glandular cells, provides protection to the underlying epithelium, and plays a role in cell signaling. ${ }^{(5,7,8)}$

There is a need for research to determine whether the expression of MUC-1 changes during implantation. In addition, are there external variables that contribute to changes in MUC-1 expression that interfere with endometrial receptivity. In normal women, MUC-1 is produced in functional endometrium, especially to increase the apposition to endometrial stroma. ${ }^{(7,9)}$

At present, endometrial receptivity studies in PCOS are still needed to find out the causes or markers that can be used to detect implantation failures in those who are infertile, especially in PCOS. Since implantation failure is almost $75 \%$, ${ }^{(2)}$ it is important to determine whether these markers affect the implantation failure rate in PCOS. The novelty of this study lies in the effect of external factors on changes in MUC-1 expression.

The endometrium in PCOS patients has a higher expression of MUC-1 than in normal women. ${ }^{(10)}$ A systematic review showed controversy with respect to whether MIC-I is significantly higher or lower in women with PCOS compared to healthy women. ${ }^{(11)}$

A study on 78 women with recurrent implantation failure found that age, body mass index (BMI), and menstrual cycle length were not significantly associated with endometrial MUC-1. ${ }^{(7)}$ The presence of MUC-1 can cause failure of embryo implantation during the apposition phase. Therefore it is necessary to discover how exactly the expression of MUC-1, a glycoprotein on epithelial cells, and other modulators are expected to play a major role in embryo implantation in women with PCOS resulting in implantation dysfunction because of imbalance in the trophoblast apposition process. ${ }^{(7)}$ The objective of this study was to investigate differences in endometrial MUC-1 expression between women with PCOS and normal women, and to determine the effect of PCOS on MUC1 expression by considering all existing external variables.

\section{METHODS}

\section{Research design}

A cross-sectional study was conducted in the outpatient clinic of Dr. Moewardi General Hospital, Surakarta, from June until November 2019.

\section{Research subjects}

The study sample was taken by a nonrandom consecutive sampling, with the subjects signing the participation agreement form with regard to the research activities (informed consent). The sample size was determined with effect size $=0.7, \alpha=0.05$ and $\beta=0.2$, and was 30 for each group. The subjects were divided into two groups of 30 PCOS women and 30 normal women, respectively, who were between 25 and 40 years old. The inclusion criteria were infertile PCOS women who met 2 of the 3 Rotterdam criteria:(12-14) 1) oligo-ovulation or anovulation defined as $<8$ menstrual cycles in the past year, 
2) hyperandrogenism (hirsutism or acne), with hirsutism defined by a Ferriman-Gallwey (FG) self-reported score of $\geq 5$ (for Asian), 3) polycystic ovaries (PCO) as detected by transvaginal ultrasound (TVUS) with 12 follicles of $2-9 \mathrm{~mm}$ diameter, and age $23-40$ years. The controls were 30 normal women who were undergoing sterilization and/or routine VIA (visual inspection with acetic acid) screening, history taking and gynecological examinations, and not suspected of suffering from PCOS (no pelvic pain, no history of dysmenorrhea or dyspareunia, normal clinical gynecological examination). Exclusion criteria were normal women with malignancies, not agreeing to become research subjects, using hormonal contraceptives, having androgen excess disorder, being at risk of hypertension, endometriosis and diabetes mellitus.

\section{Exposure data}

Data on lifestyle and reproductive exposures, as well as anthropometric measures, were collected, including age, age at menarche, menstrual problems, menstrual cycles. and BMI.

\section{Immunohistochemistry}

The expression of MUC-1 in PCOS was determined by endometrial biopsy in the luteinizing hormone ( $\mathrm{LH})$ secretory phase, at $\mathrm{LH}$ +5 days until $\mathrm{LH}+10$ days by endometrial sampling with the Pipelle curette, $2-3 \mathrm{~cm}$ below the uterine fundus. The endometrial biopsy was then put into a bottle with buffered formalin and sent to the Pathological Anatomy department of Dr. Sardjito Hospital in Yogyakarta for immunohistochemical examination (IHC) of MUC-1 expression using mouse MUC-1 monoclonal antibody (Novocastra NCL-MUC1 from Vision BioSystems). In the present study, the points in time of $\mathrm{LH}+5$ days to $\mathrm{LH}+10$ days were used, because at these time points there are surges in endometrial receptivity after ovulation, at which the endometrial secretory phase and receptivity for optimal implantation can occur. The expression of MUC-1 was calculated based on observations of 200 luminal epithelial and glandular cells, using a microscope at 40x10 magnification. The number of positive (=brown-colored) cells was counted, then the results were divided by 200 and expressed as a percentage.

\section{Statistical analysis}

An independent t-test and multivariate linear regression was used to analyze the data. For statistical analysis the IBM-SPSS statistics program version 21 was used, with significance set to a $\mathrm{p}$ value of $<0.05$

\section{Ethical clearance}

Ethical clearance was obtained from the Health Research Ethics Commission of Dr. Moewardi Hospital/Faculty of Medicine, Universitas Sebelas Maret, Surakarta, Central Java, Indonesia under No.744/X/HREC/2018 dated 29 October 2018.

\section{RESULTS}

Table 1 shows the mean values of the variables of age, menstrual problems, menstrual cycle, age at menarche, BMI, and MUC- 1 for the groups of PCOS and normal women. There were significant differences between the two groups with regard to menstrual cycle $(27.88 \pm$ 2.39 vs $28.06 \pm 2.40$ days; $p=0.040)$; age at menarche $(14.31 \pm 2.19$ vs $13.36 \pm 1.21$ years; $\mathrm{p}=0.028)$, and MUC-1 (49.66 $\pm 47.79 \%$ vs 7.66 $\pm 14.55 \%$; $\mathrm{p}=0.03)$. The differences in age, menstrual problems, and BMI were not significant (Table 1).

All external variables, such as age, menstrual problems, menstrual cycle, age at menarche, BMI and PCOS were entered into the multivariate linear regression model. There was a statistically significant association of $\operatorname{PCOS}(\beta=29.54 ; 95 \%$ CI 9.57-49.49; $p=0.004)$, and BMI $(\beta=29.99 ; 95 \%$ CI 5.91-54.07; $\mathrm{p}=0.016$ ) with MUC-1. However, there were no significant differences in age, menstrual problems, menstrual cycle, and age at menarche. 
Table 1. Means of several variables in PCOS and normal women

\begin{tabular}{lccc}
\hline \multirow{2}{*}{ Variables } & \multicolumn{2}{c}{ Means of several } & p value \\
\cline { 2 - 3 } & PCOS $(\mathbf{n}=\mathbf{3 0})$ & Normal $(\mathbf{n}=\mathbf{3 0})$ & 0.058 \\
\hline Age (years) & $33.75 \pm 5.38$ & $31.70 \pm 4.71$ & 0.718 \\
Menstrual problem & $34.00 \pm 11.33$ & $28.77 \pm 5.25$ & $0.040^{*}$ \\
Menstrual cycle (days) & $27.88 \pm 2.39$ & $28.06 \pm 2.40$ & $0.028^{*}$ \\
Age at menarche (years) & $14.31 \pm 2.19$ & $13.36 \pm 1.21$ & 0.052 \\
BMI $\left(\mathrm{kg} / \mathrm{m}^{2}\right)$ & $23.18 \pm 3.02$ & $22.24 \pm 2.19$ & $0.03^{*}$ \\
MUC-1 $(\%)$ & $49.66 \pm 47.79$ & $7.66 \pm 14.55$ & \\
\hline
\end{tabular}

PCOS $($ Beta $=0.37)$ was more important than BMI (Beta $=0.30)$ in increasing the MUC-1 (Table 2).

Furthermore, endometrial tissue samples were examined by immunohistochemical methods in PCOS and normal women, then observations were made using a microscope at $40 \times 10$ magnification to obtain a visual representation of MUC-1 levels as shown in Figure $1(\mathrm{~A})$ and $(\mathrm{B})$.

In Figure 1 (A) the cytoplasm and glandular stroma are clear (show no color), while in Figure1 (B) they are brown in color. Thus, the results of immunohistochemical expression of MUC-1 in luminal endometrial epithelium and glandular stroma in the secretory phase showed that PCOS women had a higher MUC-1 expression than normal women. MUC-1 expression appears brown in the cytoplasm and glandular stroma.

\section{DISCUSSION}

The results showed that there was an increase in endometrial MUC-1 expression in $\mathrm{P} \bigcirc \mathrm{OS}$ compared to normal wome $\mathrm{i}$, resulting in a decrease in endometrial receptivity. The high levels of MUC-1 also caused impaired endometrial reception which will affect the embryo implantation adhesion process in the endometrial wall. Thus, it could be concluded that MUC-1 had an effect on endometrial receptivity. Therefore, it is necessary to conduct early detection of MUC-1 as biomarker of endometrial receptivity to increase the numbers of successful implantations. In addition, estrogen in PCOS also causes endometrial dysfunction associated with increased MUC-1 levels. ${ }^{(11,12)}$ A previous study showed that failure of embryo implantation was related to abnormal endometrial expression of MUC-1. ${ }^{(13)}$ A higher than normal MUC-1 level causes a decrease in endometrial receptivity. Excessive MUC-1 expression in the endometrium in PCOS will influence the changes in embryo adhesion to the endometrial wall during implantation. MUC-1 is one of the many biomarkers needed during blastocyst adhesion to the endometrial wall and MUC-1 also plays an important role in the embryo during the blastocyst stage. ${ }^{(11)}$ Other studies have also shown in their research results that MUC-1 is only one of several biomarkers that are deregulated in the endometrium of patients with PCOS. ${ }^{(9)}$

Table 2. Multivariate linear regression model of demographic and clinical characteristics with MUC-1

\begin{tabular}{lcccc}
\hline \multicolumn{1}{c}{ Independent variables } & $\boldsymbol{\beta}$ & Beta & $\mathbf{9 5 \%}$ C.I. & p value \\
\hline Age & 1.35 & 0.01 & $-18.78-21.49$ & 0.893 \\
Menstrual problems & -0.19 & -0.01 & $-25.49-25.10$ & 0.988 \\
Menstrual cycle & 7.81 & 0.07 & $-17.90-33.53$ & 0.545 \\
Age at menarche & 2.72 & 0.03 & $-17.92-23.38$ & 0.792 \\
BMI & 29.99 & 0.30 & $5.91-54.07$ & $0.016^{*}$ \\
PCOS & 29.54 & 0.37 & $9.57-49.49$ & $0.004^{*}$ \\
\hline
\end{tabular}



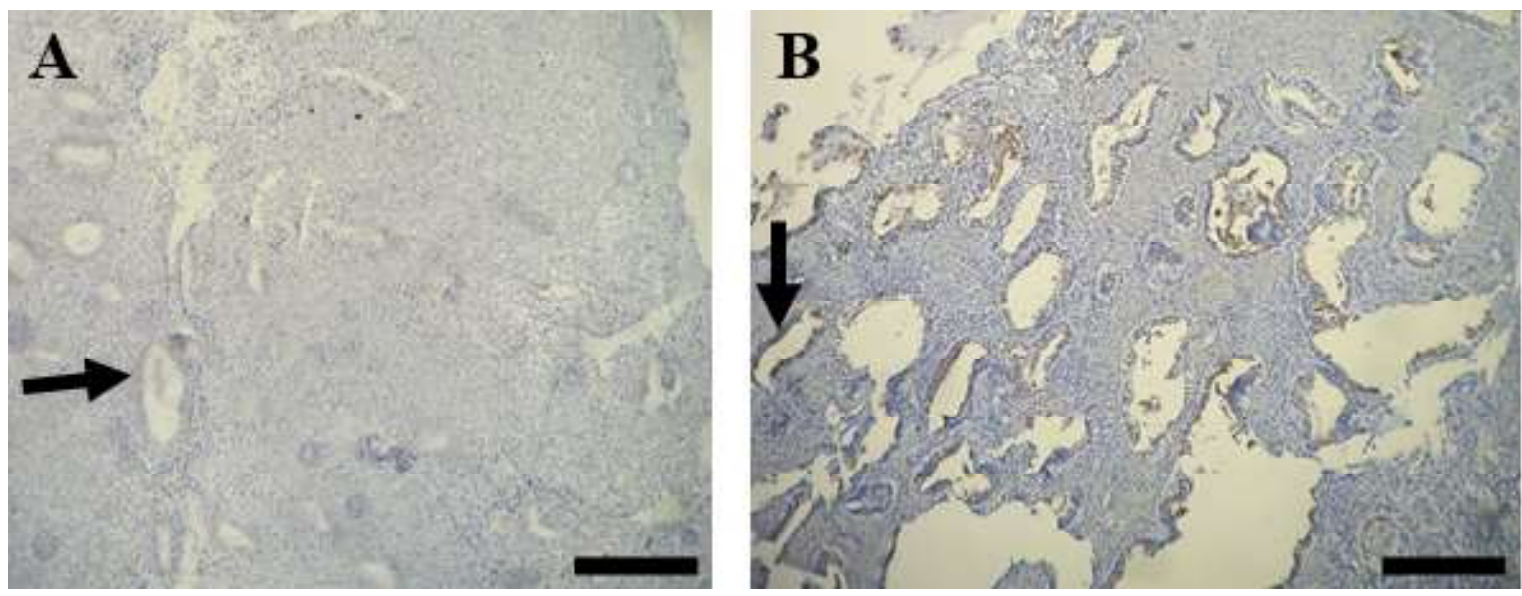

Figure1. Immunohistochemistry of MUC-1 expression in endometrium. (A) normal group, (B) PCOS group.

Black bar: $10 \mu \mathrm{m}$; $\uparrow:$ MUC-1 Expression

Infertile patients may suffer recurrent implantation failure, since embryo implantation needs a series of molecular interactions between the embryo and the maternal uterus. ${ }^{(15)}$ The event needed during the implantation process is endometrial reception, so that the embryo can function normally at the blastocyst stage resulting in the emergence of the complex interaction dialog between the embryo and the endometrium. This dialog can occur if there is a synchronization between oocyte and endometrial maturation, followed by blastocyst orientation in the endometrial wall. In the early stages of implantation involving bi-directional molecules between the blastocyst and endometrium about 6-12 days after ovulation, this dialog is very important for success. ${ }^{(16)}$ The implantation includes apposition, adhesion, and invasion through the endometrial wall. This means that embryo implantation is the result of many well-functioning processes, including cellular adhesion, invasion, and decidualization of the endometrium. ${ }^{(15,17)}$ Part of the immune system mechanism is regulated by genetic expression of ovarian hormones. During most of the menstrual cycle, the endometrium basically rejects the embryo. In order to reverse this endometrial condition and make an implantation process possible, a physiological effort is needed. During the beginning of the menstrual cycle, the estrogen level increases to enhance endometrial cell proliferation. When ovulation occurs, the progesterone secreted by the luteinizing follicle leads to cell differentiation. Therefore, the endometrium is in a mature and optimal condition for embryo implantation. ${ }^{(7,18)}$ Endometrial receptivity is physiologically marked by pinopodes, specific projections on the surface of the endometrial epithelial membrane, as a morphologic sign of endometrium receptivity. Expression of pinopodes is limited to a brief period, with a maximum of two days in the menstrual cycle during the implantation window. Blastocyst attachment is seen to be located on the top of endometrial pinopodes. ${ }^{(19)}$

The results of the present study showed that there was an increase in endometrial MUC-1 expression in PCOS compared to normal women, causing a decrease in endometrial receptivity. This increased MUC-1 will also cause impaired endometrial reception, which will affect the embryo implantation adhesion process in the endometrial wall. Thus, it could be concluded that MUC-1 has an effect on endometrial receptivity. Therefore, it is necessary to conduct early detection of MUC-1 as biomarker of endometrial receptivity to increase implantation success rate. In addition, estrogen in PCOS also causes endometrial dysfunction associated with increased MUC-1 levels..$^{(11,12)}$ 
During implantation, MUC-1 reduction is localized on specific receptor area. Mucin-1 expression rate on the uterine surface greatly decreases during the conception attachment period and the endometrium is exposed to stimulation by progesterone. ${ }^{(20)}$ There is a correlation between MUC-1 expression and progesterone receptors due to the presence of the embryo going to be implanted. (21) Then, MUC-1 will disappear followed by the loss of progesterone receptors. MUC-1 epithelial synthesis is stimulated by progesterone, it will cause the loss of epithelial progesterone from the uterus. As a consequence, MUC-1 production decreases and enables a receptive condition for conception attachment. ${ }^{(9)}$ Increased MUC-1 expression in PCOS causes the endometrial surface to be non-receptive, because of the anti-adhesive characteristic of MUC-1. Hence, an increase in MUC-1 expression decreases the occurrence of implantation or is anti-adhesive. A higher than normal increase in MUC-1 expression will interrupt embryo attachment to the endometrial wall, and this will cause higher progesterone receptor needs and impair embryo adhesion. ${ }^{(17)}$ The limitation of this study were lutheal phase length, prolaktin levels, ovulation confirmation, uterine cavity shape or level progesterone were not measured.

The clinical implication of this study is that in the application of Assisted Reproductive Technology (ART) attention should be paid to the MUC-1 marker, to increase the implantation success rate. Directions in further studies are the provision of adequate anti-MUC-1 and progesterone to improve endometrial receptivity so that implantation can occur.

\section{CONCLUSIONS}

The level of endometrial MUC-1 expression in PCOS was higher than in normal women. The higher expression of MUC-1 in PCOS causes an endometrial receptivity defect and decreases embryo implantation.

\section{CONFLICT OF INTEREST}

Competing interests: No relevant disclosures.

\section{ACKNOWLEDGEMENT}

We would like to express our heartfelt thanks to the Director of Dr. Moewardi Hospital, Dr. Suharto Wijanarko, dr., Sp.U for his permission and cooperation for the conduct of this research in above-mentioned hospital.

\section{CONTRIBUTORS}

All authors contributed to conception and design of the study; YPM contributed to data acquisition; all authors contributed to analysis and/or interpretation of data. URB drafted the manuscript; URB, SS and EM contributed to revising the manuscript critically for important intellectual content. All authors have read and approved the version of the manuscript to be published.

\section{REFERENCES}

1. Savaris RF, Groll JM, Young SL, et al. Progesterone resistance in PCOS endometrium: a microarray analysis in clomiphene citrate-treated and artificial menstrual cycles. J Clin Endocrinol Metab 2011;96:1737-46. doi: 10.1210/jc.2010-2600.

2. Li SY, Song Z, Song MJ, Qin JW, Zhao ML, Yang ZM. Impaired receptivity and decidualization in DHEA-induced PCOS mice. Sci Rep 2016;6:1-10. http://dx.doi.org/10.1038/srep38134.

3. Bashiri A, Halper KI, Orvieto R. Recurrent implantation failure - update overview on etiology, diagnosis, treatment and future directions. Reprod Biol Endocrinol 2018;16:1-18. doi: 10.1186/s12958-018-0414-2.

4. Cha J, Sun X, Dey SK. Mechanisms of implantation: strategies for successful pregnancy. Nat Med 2012;18:1754-67. http://dx.doi.org/ 10.1038/nm.3012.

5. Davidson LM, Coward K. Molecular mechanisms of membrane interaction at implantation. Birth Defects Res Part C - Embryo Today Rev 2016;108: 19-32.

6. Piltonen TT. Polycystic ovary syndrome: endometrial markers. Best Pract Res Clin Obstet 
Gynaecol 2016;37:66-79. doi: 10.1016/j.bpobgyn. 2016.03.008.

7. Wu F, Chen X, Liu Y, et al. Decreased MUC-1 in endometrium is an independent receptivity marker in recurrent implantation failure during implantation window. Reprod Biol Endocrinol 2018;16:1-7. doi: 10.1186/s12958-018-0379-1.

8. Zeng Y, Zhang Q, Zhang Y, et al. MUC-1 predicts colorectal cancer metastasis: a systematic review and meta-analysis of case controlled studies. PLoS One 2015;10:e138049. doi:10.1371/ journal.pone.0138049.

9. Margarit L, Taylor A, Roberts MH, et al. MUC-1 as a discriminator between endometrium from fertile and infertile patients with PCOS and endometriosis. J Clin Endocrinol Metab 2010;95:5320-9. doi: 10.1210/jc.2010-0603.

10. Lopes IM, Maganhin CC, Oliveira-Filho RM, et al. Histomorphometric analysis and markers of endometrial receptivity embryonic implantation in women with polycystic ovary syndrome during the treatment with progesterone. Reprod Sci 2014;21:930-8.

11. Baracat MCP, Serafini PC, Simões RDS, Maciel GAR, Soares JM, Baracat EC. Systematic review of cell adhesion molecules and estrogen receptor expression in the endometrium of patients with polycystic ovary syndrome. Int J Gynecol Obstet 2015;129:1-4. doi: 10.1016/j.ijgo.2014.10.022.

12. Hu M, Li J, Zhang Y, et al. Endometrial progesterone receptor isoforms in women with polycystic ovary syndrome. Am J Transl Res 2018;10:2696-705.

13. Bastu E, Mutlu MF, Yasa C, et al. Role of mucin 1 and glycodelin A in recurrent implantation failure. Fertil Steril 2015;103 : 1059-64. http://dx.doi.org/ 10.1016/j.fertnstert.2015.01.02521.

14. Yang Y, Han Y, Wang W, et al. Assessing new terminal body and facial hair growth during pregnancy: toward developing a simplified visual scoring system for hirsutism. Fertil Steril 2016;105: 494-500. DOI: https://doi.org/10.1016/ j.fertnstert.2015.10.036.

15. Fukui $Y$, Hirota $Y$, Matsuo $M$, et al. Uterine receptivity, embryo attachment, and embryo invasion: Multistep processes in embryo implantation. Reprod Med Biol 2019;18:234-40. doi: $10.1002 / \mathrm{rmb} 2.12280$.

16. Parks JC, McCallie BR, Patton AL, et al. The impact of infertility diagnosis on embryoendometrial dialogue. Reproduction 2018;543-52. doi: 10.1530/REP-17-0566.

17. Raheem KA. Cytokines, growth factors and macromolecules as mediators of implantation in mammalian species. Int J Vet Sci Med 2018;6 Sup1:S6-14. https://doi.org/10.1016/j.ijvsm.2017. 12.001 .

18. Craciunas L, Gallos I, Chu J, et al. Conventional and modern markers of endometrial receptivity: a systematic review and meta-analysis. Hum Reprod Update 2019;25:202-23. doi: 10.1093/humupd/ dmy044.

19. Altmäe S, Koel M, Võsa U, et al. Meta-signature of human endometrial receptivity: a meta-analysis and validation study of transcriptomic biomarkers. Sci Rep 2017;7: 10077. doi: 10.1038/ s41598-017-10098-3.

20. Redzovic A, Laskarin G, Dominovic M, Haller M, Rukavina D. Mucins help to avoid alloreactivity at the maternal fetal interface. Clinl Develop Immunol 2013, Article ID 542152, 9 pages. http:// dx.doi.org/10.1155/2013/54215.

21. Shen F, Yan C, Liu M, Feng Y, Chen Y. Decreased expression of mucin-1 in endometriosis endometrium correlated with progesterone receptor B involved in infertility. Arch Gynecol Obstet 2015;291:439-45. DOI: 10.1007/s00404014-3419-x. 